\title{
Original Article OUT-OF-POCKET EXPENDITURE OF THE HOSPITALIZED PATIENTS FOR TREATMENT OF LIVER CIRRHOSIS IN A TERTIARY HOSPITAL
}

\author{
Mohammad Farhadul Haque ${ }^{1}$, ANM Shamsul Islam ${ }^{2}$, Emily Akter ${ }^{3}$, Sk. Md. Ershad ${ }^{4}$ Kazi Md. Israfil $^{5}$
}

\begin{abstract}
Background: Out-of-pocket expenditure is the major financer for health care expenses in Bangladesh, causing financial burden on affected households. Chronic disease like liver cirrhosis requires long term treatment, exposing households to further economic stress, pushing them into a state where they fail to meet the necessary health expenses from their own household consumption and sacrifices basic necessities of living to pay for healthcare services. This study aims to estimate the OOP expenditure and resulting catastrophic health expenditure among hospitalized patients of liver cirrhosis.

Methods: This was a cross-sectional study conducted among 42 diagnosed liver cirrhosis patients admitted at Bangabandhu Sheikh Mujib Medical University (BSMMU) under the department of hepatology and department of gastroenterology, aged 18 years and above. Convenient sampling technique was used and data were collected from the respondents using a semi-structured questionnaire through face-to-face interview during discharge from hospital.

Results: Out of pocket expenditure for liver cirrhosis at BSMMU was BDT 24,898. Direct medical cost was BDT 21,202, direct non-medical cost was BDT 1,895 and indirect cost was BDT 1,801. Among the determinants of OOP healthcare expenditure, medicine and investigation costs were the major cost drivers, $36.91 \%$ and $44.13 \%$ of the total expenditure, respectively. OOP expenditure was found to be slightly higher among respondents from department of hepatology, than department of gastroenterology, BDT 21,834 and BDT 18,043 respectively, but this difference was not statistically significant. At $10 \%$ threshold level, $40.5 \%$ of the respondents were affected by Catastrophic Healthcare Expenditure (CHE). Nearly one-third (30.9\%) of the respondents were facing distress financing due to OOP Expenditure.
\end{abstract}

Conclusions: The high amount of OOP expenditure can be contributed mostly to the high cost of medicine and investigation. Making medicine readily available at an affordable price along with rational use of medication and investigation for diagnostic purpose can help reduce this financial burden on affected households.

JOPSOM 2020; 39(2): 74-82

https://doi.org/10.3329/jopsom.v39i2.53169

Keywords: Out-of-pocket Expenses, Liver Cirrhosis, Catastrophic Health Expenditure, Distress Financing, Tertiary Hospital

1. Assistant Director Hospital, Shaheed Monsur Ali Medical College Hospital, Dhaka - 1215, Bangladesh. Email: farhadulhaque@gmail.com

2. Associate Professor, Department of Public Health and Hospital Administration, National Institute of Preventive and Social Medicine, Mohakhali,Dhaka, E-mail: masumsislam@yahoo.com

3. Assistant Professor, Department of Dermatology and Venerology, Enam Medical College and Hospital, Dhaka, Bangladesh.E-mail: emilyhaq@ gmail.com

4. Registrar, Department of Nephrology, National Institute of Kidney Diseases \& Urology, Dhaka - 1207. Email: smershad990@gmail.com

5. Lecturer, Dental Public Health Department, Dhaka Dental College.E-mail: drisrafil47@gmail.com

Correspondence: Mohammad Farhadul Haque.E-mail: farhadulhaque@gmail.com

\section{INTRODUCTION}

In a middle-income country like Bangladesh, only a part of the total healthcare expenditure (THE) is paid by the government and the rest is paid by the households in the form of out-of-pocket (OOP) expenditure ${ }^{1-3}$. Like most Asian countries, where OOP 
expenditure is the primary means of healthcare financing and its proportion to THE varies from 30$82 \%$ from country to country, Bangladesh depends heavily on OOP expenditure for health, OOP expenditure, as proportion of total health expenditure was $62.4 \%$ in 2003, which increased to $67 \%$ in $2015^{4}$ and further increased to $73.9 \%$ in 2017 , showing an average growth rate of $1.22 \% \%^{5}$. In Bangladesh, healthcare expense was $3.4 \%$ of GDP with a per capita health expenses of $\$ 27$ on 2015. On 2017, healthcare expense reduced to $2.3 \%$ of the countries GDT with an increased per capita health expense of $\$ 36^{4,5}$. Since cost for healthcare services has always been high in Bangladesh ${ }^{3}$, it imposes undue financial burden on affected household, exposing them to catastrophic health expenditure (CHE) where they have to spend more than $10 \%$ of their yearly consumption on health, sacrificing basic necessities of life ${ }^{6}$. In extreme cases, households can't pay for their yearly consumption and resort to borrowing money for health expenses or selling property. Being unable to recuperate from these expenses, households often slip into poverty and overtime as debts accumulates and in chronic diseases as healthcare expenses continue to aggregate, households ultimately slip further down the poverty line $^{7}$. High OOP expenditure is responsible for causing impoverishment for 25 million households globally each year ${ }^{8}$ and this kind of impoverishing effect is more acutely felt in low or middle income countries like Bangladesh, where rates of poverty is already high $^{3}$, as $25.5 \%$ of the country population lives below poverty line and $12.3 \%$ lives below extreme poverty line ${ }^{9,10}$. Each year another $4.2 \%$ falls to extreme poverty due to high OOP expenditure for health ${ }^{11}$.

Liver diseases like cirrhosis of liver have become a major public health issue ${ }^{12}$ and the ever evolving demographic and epidemiological trends have pushed liver diseases to cause substantial economic burden worldwide $^{13}$. Within a few decades, liver diseases have become a leading cause of mortality and morbidity worldwide irrespective of age, sex or ethnicity ${ }^{14}$. Globally near a billion people suffer from liver diseases with 2 million deaths per year, contributing to $3.5 \%$ of all deaths worldwide ${ }^{15}$. Estimated global prevalence of liver cirrhosis is $8.5 \%{ }^{16}$ with complications from liver cirrhosis being the $11^{\text {th }}$ most common cause of mortality worldwide ${ }^{17}$.

While there are researches being conducted on the prevalence and distribution of liver cirrhosis among Bangladeshi population, we couldn't find any research that addresses the issues of economic burden of liver cirrhosis treatment among hospitalized patients in Bangladesh. An evaluation of out-of-pocket expenditure of hospitalized patients with liver cirrhosis will give us a better understanding of the economic impact of liver cirrhosis on affected households. Prevalence of catastrophic health expenditure and distress financing due to OOP expenditure for liver cirrhosis were also estimated.

\section{METHODS}

This was a cross-sectional study, conducted among liver cirrhosis patients admitted at Bangabandhu Sheikh Mujib Medical University (BSMMU), under the department of hepatology and department of gastroenterology, aged 18 years and above between January 2019 and December 2019. A total of 42 patients matching the selection criteria were interviewed during the data collection period, from April to September, 2019. Selection criteria included hospitalized and already diagnosed cases of liver cirrhosis patients. Each patient was interviewed once, using a pretested semi structured questionnaire during their discharge from the hospital. During interview, detailed socio-demographic and socio-economic data such as age, sex, housing status, residence, education, monthly household income and expenses, and source of healthcare expenses were taken. Also, data on duration of diagnosed disease, duration of hospital stay, number of hospitalizations in last six months and types of hospital beds were taken.

Data on cost for investigations, medical supplies, medicines, blood transfusion and bed rent were collected and used to calculate direct medical cost. Data on cost for travel and dietary needs of the patients were collected and used to calculate direct nonmedical cost. Data on unofficial payments and cost for travel and dietary needs for the attendants were taken and used to calculate indirect cost. Combining the direct medical cost, direct non-medical cost and indirect cost generated the total out-of-pocket expenditure for liver cirrhosis treatment at BSMMU. OOP expenditure induced catastrophic healthcare expenditure (CHE) and resulting distress financing were evaluated. $\mathrm{CHE}$ was defined as any OOP expenditure on healthcare exceeding $10 \%$ of total yearly income of the household. Distress financing was defined as when a household borrowed money or sold property to meet the OOP expenditure for health care. Statistical analyses were carried out by using Statistical Package for Social Sciences version 25.0 for Windows. Necessary ethical clearance for the study was sought from the Institutional Review Board of National Institute of Preventive and Social Medicine (NIPSOM) and concerned authorities of Bangabandhu Sheikh Mujib Medical University (BSMMU). 


\section{RESULTS}

\section{Sociodemographic characteristics of the study population}

Study population included 42 liver cirrhosis patients from BSMMU, $83.3 \%$ from Department of Hepatology and $16.7 \%$ from Department of Gastroenterology, as shown in Table 1. Men were $66.7 \%$ of the study population and women were $33.3 \%$. Age group 45 to 59 years had $47.6 \%$ of the study population. Study population were predominantly Muslim (92.9\%) and from rural areas $(64.3 \%)$. Highest proportion (28.6\%) of respondents were from Dhaka division, followed by Rajshahi and Khulna, $16.7 \%$ and $14.3 \%$ respectively. Among the study population $50.0 \%$ have completed primary education and $26.2 \%$ have completed SSC. Monthly family income was between BDT 10 to 20 thousand for $47.6 \%$ of the patients and monthly family expense was between BDT 10 to 15 thousand for $28.6 \%$. Duration of diagnosed disease was 6 months to 1 year for $73.8 \%$ of the patients and 59.55 patients stayed at the hospital for up to 1 week. Patients with more than one visit in last 6 months prior to this study were $14.3 \%$ and $78.6 \%$ stayed in non-paying bed.

Table 1: Sociodemographic characteristics of the study population $(n=42)$

\begin{tabular}{|c|c|c|}
\hline Criteria & Frequency & Percentage \\
\hline \multicolumn{3}{|l|}{ Age group } \\
\hline 18 to 29 years & 3 & 7.1 \\
\hline 30 to 44 years & 9 & 21.4 \\
\hline 45 to 59 years & 20 & 47.6 \\
\hline 60 and above & 10 & 23.8 \\
\hline \multicolumn{3}{|l|}{ Sex } \\
\hline Male & 28 & 66.7 \\
\hline Female & 14 & 33.3 \\
\hline \multicolumn{3}{|l|}{ Housing } \\
\hline Rural & 27 & 64.3 \\
\hline Urban & 15 & 35.7 \\
\hline \multicolumn{3}{|l|}{ Residence } \\
\hline Dhaka & 12 & 28.6 \\
\hline Rajshahi & 7 & 16.7 \\
\hline Khulna & 6 & 14.3 \\
\hline Barisal & 5 & 11.9 \\
\hline Chittagong & 5 & 11.9 \\
\hline Rangpur & 4 & 9.5 \\
\hline Mymensingh & 2 & 4.8 \\
\hline Sylhet & 1 & 2.4 \\
\hline \multicolumn{3}{|l|}{ Education } \\
\hline Illiterate & 3 & 7.1 \\
\hline PSC & 21 & 50.0 \\
\hline SSC & 11 & 26.2 \\
\hline
\end{tabular}




\begin{tabular}{|c|c|c|}
\hline HSC & 3 & 7.1 \\
\hline Graduate & 3 & 7.1 \\
\hline Honors & 1 & 2.4 \\
\hline \multicolumn{3}{|l|}{ Study place } \\
\hline Department of Hepatology, BSMMU & 35 & 83.3 \\
\hline Department of Gastroenterology, BSMMU & 7 & 16.7 \\
\hline \multicolumn{3}{|l|}{ Socioeconomic Status } \\
\hline Middle class & 36 & 85.7 \\
\hline Lower class & 6 & 14.3 \\
\hline \multicolumn{3}{|l|}{ Monthly family income } \\
\hline Less than BDT 10 thousand & 4 & 9.5 \\
\hline From BDT 10 to 15 thousand & 10 & 23.8 \\
\hline From BDT 15 to 20 thousand & 10 & 23.8 \\
\hline More than BDT 20 thousand & 18 & 42.9 \\
\hline \multicolumn{3}{|l|}{ Monthly family expenses } \\
\hline Less than BDT 10 thousand & 10 & 23.8 \\
\hline From BDT 10 to 15 thousand & 12 & 28.6 \\
\hline From BDT 15 to 20 thousand & 10 & 23.8 \\
\hline More than BDT 20 thousand & 10 & 23.8 \\
\hline \multicolumn{3}{|l|}{ Duration of diagnosed disease } \\
\hline 6 months to 1 year & 31 & 73.8 \\
\hline More than 1 year & 11 & 26.2 \\
\hline \multicolumn{3}{|l|}{ Days stayed in hospital } \\
\hline Up to 1 week & 25 & 59.5 \\
\hline 1 to 2 weeks & 14 & 33.3 \\
\hline More than 2 weeks & 3 & 7.1 \\
\hline \multicolumn{3}{|l|}{ Frequency of hospitalization in last 6 months } \\
\hline Once & 36 & 85.7 \\
\hline Twice & 6 & 14.3 \\
\hline \multicolumn{3}{|l|}{ Types of bed } \\
\hline Non-Paying Bed & 33 & 78.6 \\
\hline Paying Bed & 9 & 21.4 \\
\hline
\end{tabular}

\section{Distribution of healthcare expenses of the study subjects}

Direct medical cost for liver cirrhosis was estimated to be BDT 21,202 (85.16\%), direct non-medical cost was
BDT 1,895 (7.61\%) and indirect cost was BDT 1,801 (7.23\%). Estimated OOP expenditure was BDT 24,898. Individual costs were measured for each category. Investigation cost and medicine cost were 
the two most major contributors in the OOP expenditure respectively. expenditure, $44.13 \%$ and $36.91 \%$ of the OOP

Table 2: Distribution of healthcare expenses of the study subjects

\begin{tabular}{|c|c|c|}
\hline Determinants of Healthcare Expenditures & Mean $( \pm$ SD) & \% OOP Expenditure \\
\hline \multicolumn{3}{|l|}{ Direct Medical Cost (in BDT) } \\
\hline Investigation cost & $10,988( \pm 8,170)$ & 44.13 \\
\hline Medical accessories cost & $536( \pm 389)$ & 2.15 \\
\hline Medicine cost & $9,190( \pm 11,645)$ & 36.91 \\
\hline Transfusion cost & $71( \pm 285)$ & 0.29 \\
\hline Bed rent & $417( \pm 864)$ & 1.67 \\
\hline Total & $21,202( \pm 18,122)$ & 85.16 \\
\hline \multicolumn{3}{|l|}{ Direct Non-Medical Cost (in BDT) } \\
\hline Cost for travel to hospital & $997( \pm 973)$ & 4.00 \\
\hline Cost for food and drinks & $898( \pm 863)$ & 3.61 \\
\hline Total & $1,895( \pm 1,298)$ & 7.61 \\
\hline \multicolumn{3}{|l|}{ Indirect Cost (in BDT) } \\
\hline Cost of food or drinks for attendant & $1,151( \pm 852)$ & 4.62 \\
\hline Cost of travel for attendant & $650( \pm 1,303)$ & 2.61 \\
\hline Total & $1,801( \pm 1,373)$ & 7.23 \\
\hline Total Out of Pocket Expenditure & $24,898( \pm 19,589)$ & 100 \\
\hline
\end{tabular}

Comparison of direct medical costs between the department of hepatology and gastroenterology

Individual cost categories were also estimated for patients from department of hepatology and gastroenterology and independent sample t-test were done to check if there were any statistically significant difference between these two departments in terms of treatment cost (Table 3). While investigation cost, medical accessories cost and medicine cost, as well as total direct medical cost were higher for patients from department of hepatology than department of gastroenterology, the difference were not statistically significant. No unofficial payments were found in our study.

Table 3: Comparison of direct medical costs between the department of hepatology and gastroenterology

\begin{tabular}{lccc}
\hline Direct Medical Costs (In BDT) & \multicolumn{2}{c}{ Mean $( \pm$ SD) } & P-value \\
\hline \multicolumn{1}{l}{ Hepatology } & Gastroenterology & \\
\hline Medical accessories cost & $11,220( \pm 8,227)$ & $9,829( \pm 8,407)$ & $0.686^{\mathrm{a}}$ \\
\hline Medicine cost & $563( \pm 419)$ & $400( \pm 100)$ & $0.318^{\mathrm{a}}$ \\
\hline Transfusion cost & $9,654( \pm 12,364)$ & $6,871( \pm 7,265)$ & $0.570^{\mathrm{a}}$ \\
\hline Bed rent & $40( \pm 165)$ & $229( \pm 605)$ & $0.443^{\mathrm{a}}$ \\
\hline Total & $357( \pm 847)$ & $714( \pm 951)$ & $0.324^{\mathrm{a}}$ \\
\hline
\end{tabular}

$\mathrm{a}=$ Independent sample $\mathrm{T}$-test was done, a $\mathrm{p}$ value $<0.05$ was considered statistically significant. 


\section{Distribution of sources of healthcare financing among the study population}

Respondents were asked about the sources of the money they have spent for the treatment of liver cirrhosis during their hospital stay. Personal or family savings were used by $69 \%$ of the respondents, $30.9 \%$ had to take loans or sell properties to meet the healthcare expenses (Figure 1). So, prevalence of distress financing among study population was $30.9 \%$.

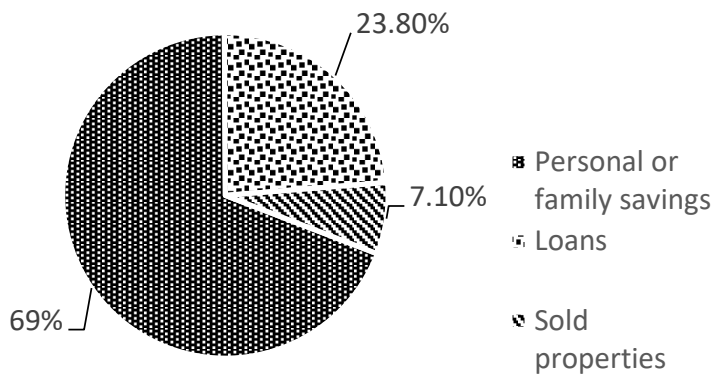

Figure 1: Distribution of sources of healthcare financing among the study population

\section{Distribution of Catastrophic healthcare expenditure at $10 \%$ cur-off level}

The prevalence of catastrophic health expenditure for hospitalization due to liver cirrhosis was calculated. At $10 \%$ cut-off value, $40.5 \%$ of the study population was found to be affected by CHE due to OOP expenditure for liver cirrhosis treatment during the period of hospitalization.

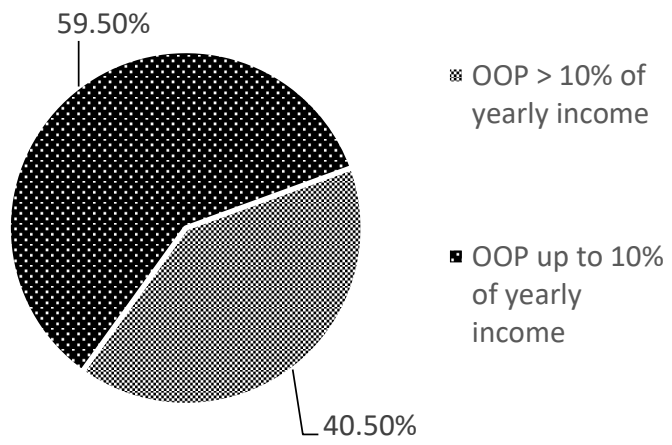

Figure 2: Distribution of Catastrophic healthcare expenditure at $10 \%$ cur-off level

\section{DISCUSSION}

In Bangladesh liver cirrhosis is one of the major noncommunicable diseases ${ }^{18,19}$. Present study was conducted to estimate the out-of-pocket expenditure of liver cirrhosis and its financial impacts in terms of distress financing and catastrophic health expenditure among hospitalized patients from BSMMU.

Overall OOP expenditure for liver cirrhosis was estimated to be BDT 24,898. Patients were collected from department of hepatology and department of gastroenterology, but no significant difference was seen between the two departments regarding out-ofpocket expenditure, which could be contributed to the fact that patients from both departments had access to same medical facilities. This study could enroll only 42 samples matching selection criteria. This was due to the lower institutional health seeking behavior $(17.3 \%)$ of Bangladeshi population ${ }^{20}$ and limited number of beds for liver disease patients in hospitals.

Patients were predominantly male and from 45 to 59 years of age group. These findings coincide with other studies among liver disease patients where male gender and an advanced age of at or above 40 years were shown to be related to higher prevalence of liver cirrhosis ${ }^{18,21,22}$. Around two third of the patients were from rural areas which is also similar the findings from other studies where rural people were shown to be more likely to come to public hospitals ${ }^{23,24}$.

Overall OOP expenditure was estimated to be BDT 24,898 in present study. In a population-based study ${ }^{25}$, OOP expenditure for liver disease was shown to be BDT 2,695, which is substantially lower than current study findings. A reason for this difference could be the study design used in our study. We have collected data from only hospitalized patients, who generally needs more medications and investigations ${ }^{26}$, where Rahman MM et al. 2020 study counted OOP expenditure from households. In India, OOP expenditure was shown to be INR 17,79427 (BDT 22,627; using average exchange rate in $2014^{28}$, BDT $1=$ INR 0.7864 ) for hospitalized patients with liver disease, almost similar to present study findings.

Investigation cost and medicine cost was found to be the biggest source of OOP expenditure, $44.13 \%$ and $36.91 \%$ respectively. These results are supported by previous studies on OOP expenditure, where cost for investigation and medicine were shown to be the most responsible for high OOP expenditure ${ }^{24,29-32}$. Moreover, cost for investigations is considerably high in Bangladesh ${ }^{33}$, which also contributed to the high OOP expenditure for our study population. 
In Bangladesh, government doesn't pay for all of the healthcare expenses, households have to pay for more than two third of the expenses from their yearly consumption. In this study, $40.5 \%$ of the patients were found to be spending more than $10 \%$ of their yearly consumption on healthcare as OOP expenditure for liver cirrhosis in a single admission to the hospital. Socioeconomic class could be a contributing factor as $14.3 \%$ of our study population was from lower socioeconomic class (According to Modified Kuppuswamy Socioeconomic Scale for 2019) ${ }^{34}$ and none was from upper socioeconomic class, indicating a lower ability to pay for healthcare expenses and be more affected by catastrophic health expenses.

Although prior studies have shown the prevalence of CHE to $30-51 \%$ in India ${ }^{35,36}$ which is higher than current study finding. Study among Bangladeshi general population showed the prevalence of $\mathrm{CHE}$ to be $14.2 \%^{37}$, which is considerably lower than presenting study findings. prevalence of $\mathrm{CHE}$ in present study is also higher than the global prevalence of $9.7 \%$ found in $2000,11.4 \%$ found in 2005 , and $11.7 \%$ found in 2010 due to OOP expenditures ${ }^{38}$.

Not all the patients can afford the health care expenses from their own personal or family savings. In present study, $30.9 \%$ of the patients either borrowed money or sold property to pay for the health care expenses, thus being affected by distress financing. Previous study had shown prevalence of distress financing to be $26.1 \%$ among Bangladeshi households ${ }^{20}$ and $29.4 \%$ among hospitalized patients with liver disease ${ }^{27}$. both of these results are comparable to presenting study findings. Presenting study showed, $23.8 \%$ of the respondents were borrowing money to pay for healthcare expenses. Other studies have shown a varying degree of population to be borrowing money for healthcare expenses at $9-29 \%{ }^{32,36}$.

\section{CONCLUSION}

Cost for medicine and investigation are the biggest driver for OOP expenditure. Decentralizing the healthcare facilities towards periphery and making medicines and provisions for necessary investigations there at an affordable cost along with rational use of these facilities will help to reduce the OOP expenditure and consequently its impact on affected households.

\section{REFERENCES}

1. van Doorslaer E, O’Donnell O, Rannan-Eliya RP, et al. Effect of payments for health care on poverty estimates in 11 countries in Asia: an analysis of household survey data. Lancet. 2006;368(9544):1357-1364. doi:10.1016/S01406736(06)69560-3

2. van Doorslaer E, O'Donnell O, Rannan-Eliya $\mathrm{RP}$, et al. Catastrophic payments for health care in Asia. Health Econ. 2007;16(11):1159-1184. doi:10.1002/hec.1209

3. Huq NM, Al-Amin AQ, Howlader SR, Kabir MA. Paying out of pocket for healthcare in Bangladesh - A burden on poor? Iran J Public Health. 2015;44(7):1024-1025.

4. Bangladesh National Health Accounts 19972015 (BNHA-V).; 2018. Accessed October 16, 2020.

https://www.researchgate.net/publication/327545

331_Bangladesh_National_Health_Accounts_19 97-2015_BNHA-V

5. WORLD DATA ATLAS. Bangladesh - Out of pocket expenditure as a share of current health expenditure. Published 2020. Accessed October 16, 2020.

https://knoema.com/atlas/Bangladesh/topics/Hea lth/Health-Expenditure/Out-of-pocketexpenditure-as-a-share-of-current-healthexpenditure

6. Azzani M, Roslani AC, Su TT. Determinants of household catastrophic health expenditure: A systematic review. Malaysian J Med Sci. 2019;26(1):15-43. doi:10.21315/mjms2019.26.1.3

7. Khan JAM, Ahmed S, Evans TG. Catastrophic healthcare expenditure and poverty related to out-of-pocket payments for healthcare in Bangladesh- A n estimation of financial risk protection of universal health coverage. Health Policy Plan. 2017;32(8):1102-1110. doi:10.1093/heapol/czx048

8. Xu K, Evans DB, Kadama P, et al. Understanding the impact of eliminating user fees: Utilization and catastrophic health expenditures in Uganda. Soc Sci Med. 2006;62(4):866-876. doi:10.1016/j.socscimed.2005.07.004

9. Kabir MA, Begum F. Rural Poverty in Bangladesh and its Associated Factors: Evidence from Micro Level Study. 2006;(October 2018).

10. Chowdhury MNM, Hossain MM. Poverty, Income Inequality and Growth in Bangladesh: Revisited Karl-Marx. Am Financ Bank Rev. 2019;4(2):1-10. doi:10.46281/amfbr.v4i2.324 
11. Huq NM, Al-Amin AQ, Howlader SR, Kabir MA. Paying out of pocket for healthcare in Bangladesh - A burden on poor? Iran J Public Health. 2015;44(7):1024-1025. Accessed October 14, 2020. http://ijph.tums.ac.ir

12. Marcellin P, Kutala BK. Liver diseases: A major, neglected global public health problem requiring urgent actions and large-scale screening. Liver Int. 2018;38(December 2017):2-6. doi:10.1111/liv.13682

13. Stepanova M, De Avila L, Afendy M, et al. Direct and Indirect Economic Burden of Chronic Liver Disease in the United States. Clin Gastroenterol Hepatol. 2017;15(5):759-766.e5. doi:10.1016/j.cgh.2016.07.020

14. Xiao J, Wang F, Wong NK, et al. Global liver disease burdens and research trends: Analysis from a Chinese perspective. J Hepatol. 2019;71(1):212-221. doi:10.1016/j.jhep.2019.03.004

15. Byass P. The global burden of liver disease: A challenge for methods and for public health. BMC Med. 2014;12(1):1-3. doi:10.1186/s12916014-0159-5

16. Mathurin P, Hadengue A, Bataller R, et al. EASL clinical practical guidelines: Management of alcoholic liver disease. J Hepatol. 2012;57(2):399-420. doi:10.1016/j.jhep.2012.04.004

17. Asrani SK, Devarbhavi H, Eaton J, Kamath PS. Burden of liver diseases in the world. J Hepatol. 2019;70(1):151-171. doi:10.1016/j.jhep.2018.09.014

18. Rahman S, Faroque Ahmed M, Jamshed Alam M, Izazul Hoque M, Ranjan Debnath C. Distribution of Liver Disease in Bangladesh: A Cross-country Study. Euroasian J HepatoGastroenterology. 2014;4(1):25-30. doi:10.5005/jp-journals-10018-1092

19. Islam A, Biswas T. Chronic Non-Communicable Diseases and the Healthcare System in Bangladesh: Current Status and Way Forward. Chronic Dis Int. 2014;1(2):1007-2.

20. Rahman MM, Gilmour S, Saito E, Sultana P, Shibuya K. Self-reported illness and household strategies for coping with health-care payments in Bangladesh. Bull World Health Organ. 2013;91(6):449-458. doi:10.2471/BLT.12.115428
21. Sajja KC, Mohan DP, Rockey DC. Age and ethnicity in cirrhosis. J Investig Med. 2014;62(7):920-926. doi:10.1097/JIM.0000000000000106

22. Kim IH, Kisseleva T, Brenner DA. Aging and liver disease. Curr Opin Gastroenterol. 2015;31(3):184-191. doi:10.1097/MOG.0000000000000176

23. Pavel MS, Chakrabarty S, Gow J. Cost of illness for outpatients attending public and private hospitals in Bangladesh. Int J Equity Health. 2016;15(1):167. doi:10.1186/s12939-016-0458-x

24. Mahumud RA, Sarker AR, Sultana M, Islam Z, Khan J, Morton A. Distribution and determinants of out-of-pocket healthcare expenditures in Bangladesh. J Prev Med Public Heal. 2017;50(2):91-99. doi:10.3961/jpmph.16.089

25. Rahman MM, Zhang C, Swe KT, et al. Diseasespecific out-of-pocket healthcare expenditure in urban Bangladesh: A Bayesian analysis. Joe W, ed. PLoS One. 2020;15(1):e0227565. doi:10.1371/journal.pone.0227565

26. Weersink RA, Taxis K, Drenth JPH, Houben E, Metselaar HJ, Borgsteede SD. Prevalence of Drug Prescriptions and Potential Safety in Patients with Cirrhosis: A Retrospective RealWorld Study. Drug Saf. 2019;42(4):539-546. doi:10.1007/s40264-018-0744-1

27. Kastor A, Mohanty SK. Disease-specific out-ofpocket and catastrophic health expenditure on hospitalization in India: Do Indian households face distress health financing? Dwivedi R, ed. PLoS One. 2018;13(5):e0196106. doi:10.1371/journal.pone.0196106

28. Bangladesh Taka to Indian Rupee Spot Exchange Rates for 2014. Accessed October 14, 2020. https://www.exchangerates.org.uk/BDTINR-spot-exchange-rates-history-2014.html

29. Rannan-Eliya RP, Unit BHE, Ltd DI. Bangladesh National Health Accounts, 1997 2007: Research Paper 39a, December 2010. Health Economics Unit; 2010. https://books.google.com.bd/books?id=VeDkNO JZZKoC

30. Tahsina T, Ali NB, Hoque DME, et al. Out-ofpocket expenditure for seeking health care for sick children younger than 5 years of age in Bangladesh: Findings from cross-sectional surveys, 2009 and 2012. J Heal Popul Nutr. 2017;36(1):33. doi:10.1186/s41043-017-0110-4 
31. Bank AD. The Impact of Out-of-Pocket Expenditures on Poverty and Inequalities in Use of Maternal and Child Health Services in Bangladesh. Published online 2010.

32. Prinja S, Bahuguna P, Duseja A, Kaur M, Chawla YK. Cost of Intensive Care Treatment for Liver Disorders at Tertiary Care Level in India. PharmacoEconomics - Open. 2018;2(2):179-190. doi:10.1007/s41669-017$0041-4$

33. Sarin DM SK, Kumar MD, Eslam M, et al. Liver diseases in the Asia-Pacific region: a Lancet Gastroenterology \& Hepatology Commission. Published online 2019. doi:10.1016/S24681253(19)30342-5

34. Mohd Saleem S. Modified Kuppuswamy socioeconomic scale updated for the year 2019. Indian J Forensic Community Med. 2019;6(1):13. doi:10.18231/2394-6776.2019.0001

35. Kastor A, Mohanty SK. Disease-specific out-ofpocket and catastrophic health expenditure on hospitalization in India: Do Indian households face distress health financing? Dwivedi R, ed. PLoS One. 2018;13(5):e0196106. doi:10.1371/journal.pone.0196106

36. Flores G, Krishnakumar J, O’Donnell O, van Doorslaer E. Coping with health-care costs: implications for the measurement of catastrophic expenditures and poverty. Health Econ. 2008;17(12):1393-1412. doi:10.1002/hec.1338

37. Khan JAM, Ahmed S, Evans TG. Catastrophic healthcare expenditure and poverty related to out-of-pocket payments for healthcare in Bangladesh- A n estimation of financial risk protection of universal health coverage. Health Policy Plan. 2017;32(8):1102-1110. doi:10.1093/heapol/czx048

38. Wagstaff A, Flores G, Hsu J, et al. Progress on catastrophic health spending in 133 countries: a retrospective observational study. Lancet Glob Heal. 2018;6(2):e169-e179. doi:10.1016/S2214109X(17)30429-1 